\title{
Starting, building and sustaining a program of research in emergency medicine in Canada
}

\author{
Philip J. Davis ${ }^{1,11}$ (1) Justin Yan ${ }^{2} \cdot$ Kerstin de Wit ${ }^{3,4} \cdot$ Patrick M. Archambault ${ }^{5} \cdot$ Andrew McRae $^{6} \cdot$ David W. Savage $^{7}$. \\ Naveen Poonai ${ }^{8} \cdot$ Marco L. A. Sivilotti $^{4} \cdot{\text { Alix } \text { Carter }^{9} \cdot \text { Shelley L. McLeod }}^{10}$
}

Received: 18 December 2020 / Accepted: 24 December 2020 / Published online: 15 February 2021

( ) The Author(s), under exclusive licence to Canadian Association of Emergency Physicians (CAEP)/ Association Canadienne de Médecine d'Urgence (ACMU) 2021

\begin{abstract}
Objective To develop pragmatic recommendations for starting, building and sustaining a program of research in emergency medicine (EM) in Canada at sites with limited infrastructure and/or prior research experience.

Methods At the direction of the Canadian Association of Emergency Physicians (CAEP) academic section, we assembled an expert panel of $10 \mathrm{EM}$ researchers with experience building programs of research. Using a modified Delphi approach, our panel developed initial recommendations for (1) starting, (2) building, and (3) sustaining a program of research in EM. These recommendations were peer-reviewed by emergency physicians and researchers from each of the panelist's home institutions and tested for face and construct validity, as well as ease of comprehension. The recommendations were then iteratively revised based on feedback and suggestions from peer review and amended again after being presented at the 2020 CAEP academic symposium.

Results Our panel created 15 pragmatic recommendations for those intending to start (formal research training, find mentors, local support, develop a niche, start small), build (funding, build a team, collaborate, publish, expect failure) and sustain (become a mentor, obtain leadership roles, lead national studies, gain influence, prioritize wellness) a program of EM research in centers without an established research culture. Additionally, we suggest four recommendations for department leads aiming to foster a program of research within their departments.

Conclusion These recommendations serve as guidance for centres wanting to establish a program of research in EM.
\end{abstract}

Keywords Emergency medicine $\cdot$ Administration $\cdot$ Research methods, implementation

\section{Résumé}

Objectif Développer des recommandations pragmatiques pour lancer, établir et soutenir un programme de recherche en médecine d'urgence (MU) au Canada dans des sites avec une infrastructure et / ou une expérience de recherche antérieure limitée.

Philip J. Davis

phil.davis@usask.ca

1 Department of Emergency Medicine, University of Saskatchewan, Saskatoon, SK, Canada

2 Division of Emergency Medicine, Department of Medicine, Western University, London, ON, Canada

3 Department of Medicine, McMaster University, Hamilton, ON, Canada

4 Department of Emergency Medicine, Queen's University, Kingston, ON, Canada

5 Department of Family and Emergency Medicine, Université Laval, Québec, QC, Canada

6 Department of Emergency Medicine, University of Calgary, Calgary, AB, Canada
7 Section of Emergency Medicine, Northern Ontario School of Medicine, Lakehead University, Thunder Bay, ON, Canada

8 Departments of Paediatrics, Internal Medicine, and Epidemiology and Biostatistics, Western University, London, ON, Canada

9 Division of EMS, Department of Emergency Medicine, Dalhousie University, Halifax, NS, Canada

10 Schwartz/Reisman Emergency Medicine Institute, Sinai Health and Division of Emergency Medicine, Department of Family and Community Medicine, University of Toronto, Toronto, ON, Canada

11 Royal University Hospital, 103 Hospital Drive, Saskatoon, SK S7N 0W8, Canada 
Méthodes Sous la direction de la section académique de l'Association canadienne des médecins d'urgence (ACMU), nous avons réuni un comité d'experts de 10 chercheurs en MU possédant de l'expérience dans le développement des programmes de recherche. En utilisant une approche Delphi modifiée, notre comité a mis en place des recommandations initiales pour 1) lancer, 2) établir et 3) soutenir un programme de recherche en MU. Ces recommandations ont été examinées par des médecins d'urgence et des chercheurs appartenant aux établissements d'origine des chacun des membres de comité et ont été testées pour leur validité apparente et conceptuelle, ainsi que leur facilité de compréhension. Les recommandations ont ensuite été fréquemment révisées en fonction des commentaires et suggestions de l'examen des pairs et modifiées à nouveau après avoir été présentées au symposium académique 2020 de l'ACMU.

Résultats Notre comité a créé 15 recommandations pragmatiques pour ceux qui ont l'intention de lancer (formation formelle en recherche, trouver des mentors, soutien local, développer un créneau, débuter à petite échelle), d'établir (financer, constituer une équipe, collaborer, publier, s'attendre à l'échec) et de soutenir (devenir un mentor, obtenir des rôles de leadership, diriger des études nationales, gagner en influence, prioriser le bien-être) un programme de recherche en MU dans des centres sans culture de la recherche établie. De plus, nous suggérons 4 recommandations aux responsables de département visant à promouvoir un programme de recherche au sein de leur département.

Conclusion Ces recommandations servent de guide aux centres qui souhaitent établir un programme de recherche en MU.

\section{Introduction}

Emergency medicine (EM) is a maturing specialty with an expanding scope of practice [1,2]. It is incumbent for EM clinicians and researchers to expand the scientific knowledge base that guides clinical and operational decisions to improve patient care. To meet these overarching goals and solidify EM's scientific foundations, research must be encouraged across the wide spectrum of settings that provide emergency care in Canada. Unfortunately, prospective researchers face many challenges when working in centres without an established research culture. These challenges include a high clinical workload; absence of dedicated and protected time for research; lack of accountability to complete a research project; and a paucity of support from fellow clinicians to pursue a career in research [3]. While previous Canadian Association of Emergency Physicians (CAEP) academic symposia have focused on building or sustaining a program of research in established academic departments, there is a noticeable gap in the literature on how to foster research in centres without established research infrastructure [4-6]. Therefore, our objective was to develop pragmatic recommendations for starting, building, and sustaining a program of research in EM in Canada at sites with limited infrastructure and/or prior experience.

\section{Methods}

At the direction of the CAEP academic section, we assembled an expert panel of $10 \mathrm{EM}$ researchers from across Canada. We used a modified Delphi approach to develop initial draft recommendations for starting, building, and sustaining a program of EM research (November 2019-January 2020). Emergency physicians and researchers from each of the panelists home institutions were then asked to review the recommendations for face and construct validity, as well as ease of comprehension (January-March 2020). Feedback from these discussions was reviewed by the panel and recommendations were iteratively revised (March-May 2020). After the initial draft recommendations were disseminated, it became evident that our panel needed to include a separate list of recommendations specifically for department heads/ leads.

These recommendations were distributed to the CAEP membership between July and September 2020 and presented at a virtual academic symposium on October 1, 2020 with attendees from the CAEP academic section and the CAEP membership at large. Feedback from the symposium attendees was reviewed and incorporated into the final recommendations presented here.

\section{Recommendations}

\section{Tips for starting a program of research}

Our panel developed five pragmatic recommendations for starting a program of research (see Box 1).

\section{Obtain formal training in research before becoming faculty}

Our panel strongly recommends Master's or Ph.D. level training focusing on clinical epidemiology, research methodology, and biostatistics, preferably early in one's career [4]. After such training has been completed, our panel recommends junior researchers be offered a 1-2 years research fellowship (under a strong mentor), to provide protected time to hone research skills, embark on projects and start developing a research niche. This fellowship should be completed prior to applying for an academic appointment as it will 
Box 1 Tips for Starting a Program of Research in Emergency Departments with limited prior infrastructure or experience

\author{
1. Get formal training in \\ research (i.e. $\mathrm{MSc}$ or $\mathrm{PhD}$ ) \\ 2. Find research mentors \\ 3. Obtain group support \\ 4. Develop a research niche \\ 5. Start small
}

Box 2 Tips for Building a Program of Research in Emergency Departments with limited prior infrastructure or experience
1. Find funds
2. Build a team
3. Collaborate
4. Publish
5. Expect some failures

extend the period of time that one is eligible for new/junior investigator grants.

\section{Find research mentors}

All researchers require mentors. In an ideal world, one's mentor would be someone working in EM with local research expertise. Our panel realizes that for someone working in a non-established research centre, this is not always possible. In these situations, our panel suggests finding at least two mentors: one with local research expertise (e.g., from another clinical or non-clinical department within the same institution) who can provide in-person support for navigating the institutional research milieu, and a second experienced EM researcher who can provide virtual mentorship for protocol development, grant writing, and the overall development of a research program. Suggestions for finding a virtual mentor include attending the annual Network of Canadian Emergency Researchers (NCER) or CAEP meetings and becoming a member of the CAEP research committee.

\section{Obtain group support}

This is no simple task and needs to be done with finesse, especially in departments reluctant to pursue research. In part, this can be accomplished through a supportive department lead, but of equal importance is for the researcher to gain their own social capital. Suggestions for this include answering clinical questions that are important to local decision makers/stakeholders (e.g., the hospital foundation, emergency medical services, community groups). Further, before introducing clinical research, the early career researcher may want to conduct studies (e.g., chart reviews, surveys, systematic reviews) that minimize the impact on the physician, nursing, and patient flow. Finally, our panel recommends engaging a potential "Nay-Sayer" during project development to elucidate challenges and barriers, as these "Nay-Sayers" will often find creative solutions that strengthen a research proposal prior to implementation.

\section{Develop a research niche}

Every emergency department has a unique patient population or clinical conditions/presentations which may lead to a research niche in line with a researcher's interests. One way to determine this specific niche is through a CAEP academic consultation [7]. Some departments may be better suited to certain methodology $[8,9]$, the study of unique patient populations [10], or a unique component in how healthcare is delivered locally $[11,12]$. Niches can change and adapt over time as patient populations, researcher interest and new priorities evolve.

\section{Start small}

We recommend junior investigators initiating a new program of research focus on small attainable victories. The initial focus in the first and second year should be completing 1-2 successful projects (peer-reviewed publications) that will help build academic and scholarly credibility. We suggest beginning with research questions that can be answered with fewer resources (e.g., health records reviews, surveys, or systematic reviews), before moving onto larger prospective or interventional studies.

\section{Tips for building a program of research}

Our panel developed five recommendations for building a program of research (see Box 2).

\section{Find funds}

To successfully build a program of research, funding is required for protected research time for the investigator and to hire ancillary staff such as a research assistant/coordinator. Sources of funding may include clinical/department funding, hospital or university grants/funds, hospital foundations, community/philanthropic partners, CAEP grants, as well as provincial and national research foundations. Generally, success will come with local grants before larger grants can be obtained. It is possible to build a research program without funding, but this requires volunteer time, mostly from undergraduate students, medical students, or residents who require a high degree of oversight and training.

\section{Build a team}

With some funding in place, researchers can begin to build a research team and establish roles. Generally, the research 
lead is the "ideas person". They should have the skills to write protocols, oversee research ethics board submissions, oversee data security and confidentiality, submit grants, and write manuscripts. The research facilitator/coordinator should look after the day-to-day implementation and operation of studies and should meet regularly with the research lead and department researchers to discuss project progress and future directions. This facilitator/coordinator would ideally be a department-level resource, but may also be funded by one specific investigator. Other members of the research team may include research contributors (e.g., staff clinicians with research interest) who provide clinical expertise and ideas for local projects; research assistants who help with data collection and entry; and research volunteers who may be medical, or undergraduate students who require close supervision and training from the coordinator and research lead.

\section{Collaborate}

It is important to collaborate and cross-pollinate with other groups at the local, provincial, and national level. Local collaborations can include other clinical (e.g., cardiology, neurosciences, radiology) or non-clinical groups (e.g., computer science, library science, engineering) as well as cross-pollination with other sub-specialists within EM (e.g., quality improvement, medical education, point-of-care ultrasound, simulation, pre-hospital care). Successful collaborations share the workload of protocol development, grant application, manuscript writing and will strengthen a grant application (e.g., adjunct methodology or biostatistical support). Provincial and national collaborations can help reach across geography and jurisdictions and include organizations such as NCER [13], the Pediatrics Research Consortium (PeRC) [14], the Canadian Critical Care Trials Group (CCCTG) [15], the Canadian Resuscitation Outcomes Consortium (CanROC) [16], and Knowledge Translation (KT) Canada [17]. Membership to these organizations is not only important for developing new research collaborations, they may also lead to participation in multi-centred studies.

\section{Publish}

The emerging researcher needs to publish. A reasonable goal is to publish at least 2-3 manuscripts a year in peerreviewed journals as first or last author. Publications can include original research, brief research reports, study protocols, narrative or systematic reviews, guidelines and recommendations, invited commentaries and editorials, and letters to the editor. A journal's impact factor should not be the sole consideration in deciding where to submit for publication, as the journal content and readership may be more relevant [18]. Further, consideration should be given to publishing in
Box 3 Tips for Sustaining a Program of Research in Emergency Departments with limited prior infrastructure or experience
1. Become a mentor

2. Assume leadership roles

3. Lead national research studies and guidelines

4. Gain departmental influence

5. Prioritize your wellness

open access journals, however, many of these journals have publication fees.

\section{Expect some failures}

Inherent in the research process is the fact that every researcher will experience rejection. The majority of grant applications are not initially funded, and manuscripts are often not accepted by the first journal they are submitted to or require multiple revisions before accepted. Researchers should learn resilience and continue to pursue research despite some expected failures. This is one key area where having a more experienced research mentor will be extremely valuable. They can suggest which funding applications may have a better chance of success and can advise which projects may not be worth pursuing.

\section{Tips for sustaining a program of research}

Our panel developed five recommendations for sustaining a program of research (see Box 3). We caution that the majority of these suggestions should not be undertaken too early as they could hamper the development of your own research program as well as your ability to be effective in a research role.

\section{Become a mentor}

Mentoring and supervising others can expand the investigator's skillset and research team. When choosing mentees, be selective as not all mentor/mentee relationships will be fruitful. Further, mentoring people at the right level is important as the needs of junior faculty and students are different. Junior faculty may require help navigating the institution's research milieu, while students and trainees will require more direction and support in completing research projects.

\section{Assume leadership roles}

Consideration should be given to obtaining new leadership roles and increasing scientific influence. Ways to do this include participating in peer review for journals, serving on a journal's editorial team, becoming a grant reviewer for a funding agency, or serving on a study steering committee or data safety monitoring board. These roles will 
increase exposure to new research methodologies and areas of research and may present opportunities for the investigator to expand their research network.

\section{Lead national research studies and guidelines}

Researchers at this level may also be looking towards leading their own multi-centre collaborations. This does not necessarily have to be a formal clinical trial and could include leading the development and implementation of national guidelines, position statements or provincial evaluation of health policies within your area of research.

\section{Gain departmental influence}

Department staff and leaders should see value in a research program. Asking each department member to commit to some level of research involvement (e.g., help identify and recruit patients for prospective studies, participate in journal club/rounds, supervise a resident research project) is important along with maintaining positive working relationships within your physician group. It is important the researcher present their progress and findings at departmental meetings and regularly highlight how research productivity benefits and raises the academic profile of the department, and not just the researcher. Finally, it is crucial to be transparent about how research funding and resources are used, especially if the physician group is contributing financially to the research program.

\section{Prioritize your wellness}

It is important for the researcher to take care of their personal wellness and not forget about other important things in life such as family, friends, community, and personal health $[19,20]$. Any researcher, especially those in junior and midcareer roles, should be selective in what they say "yes" and "no" to, and clarify the terms of any new roles and positions to ensure there is some academic, financial or personal benefit in participating.

\section{Tips for Department Head/Division Chiefs to Foster a Program of Research}

Finally, our panel believes that a program of research is unlikely to be successful without a supportive department lead. We respectfully submit four recommendations for EM department leads to support and foster a research culture (see Box 4).
Box 4 Tips for Department Heads/Division Chiefs to Foster a Program of Research in Emergency Departments with limited prior infrastructure or experience
1. Create a strategic plan

2. Foster a research culture

3. Set researchers up for success

4. Distribute funds equitably

\section{Identify strategic goals}

Many departments explicitly outline research goals within their strategic plan. When these goals are outlined, the department lead should also describe their motivations for doing so. For instance, the department lead might be motivated to embed research for intrinsic reasons (e.g., they wish to retain and/or attract bright young faculty and invigorate the group), or extrinsic reasons (e.g., the institution or hospital expects it, or a philanthropic donor wants to fund it). In exploring these motivations, department leads will come to the understanding that research priorities and measures of success will differ depending on the underlying motivations.

\section{Foster a research culture}

For ED research to be successful, it is important for the department lead to ensure that clinical operations are optimized. Clinical research functions best in a smoothly operating and efficient ED but stagnates in environments where clinicians are overwhelmed. As such, dealing with and improving ED operations is a requisite for ED research success.

\section{Set researchers up for success}

The department lead should ensure their researchers are set up for success. Importantly, researchers require protected time to optimize their productivity, and department leads must support shift reductions and schedule optimization to enable researchers to be productive and successfully manage the demands of their clinical and research workload. The department lead must also advocate for funding (e.g., through the institution or hospital foundation) for salary support. Finally, the department lead must support researchers in gaining access to and/or creating the necessary infrastructure for research, including hiring skilled personnel (e.g., methodologists, biostatisticians, research coordinators and/ or assistants, medical librarians), as well as obtaining the necessary office space and informatic tools.

\section{Distribute funds purposefully, sensibly and equitably}

Be aware that tithing clinical activities to support research can be perceived as excessive, punitive, or simply unfair. 
This can polarize a group and ultimately poison a group's desire to support research activities. Therefore, it is important for the department lead to articulate the need for research so that broad support is obtained. Once support and funds are in place, carefully consider how research funds are distributed. Specifically, there may be several department members involved in research and compensation may need to be based on research outputs or a points system (e.g., abstract acceptance, research supervision, successful grants, peer-reviewed publications), and not simply remunerated by research positions. Regardless of what financial support system is developed locally, it is important the system is flexible, transparent and robust.

\section{Conclusion}

These recommendations serve as guidance for centres wanting to establish a program of research in EM. These recommendations will help build capacity for a strong and sustainable network of new emergency researchers that will support the advancement of the discipline of EM in Canada and beyond.

\section{Compliance with ethical standard}

Conflict of interest The authors declare that they have no conflicts of interest.

\section{References}

1. Suter RE. Emergency medicine in the United States: a systemic review. World J Emerg Med. 2012;3:5-10. https://doi. org/10.5847/wjem.j.issn.1920-8642.2012.01.001.

2. Thoma B, Poitras J, Penciner R, Sherbino J, Holroyd BR, Woods RA. Administration and leadership competencies: establishment of a national consensus for emergency medicine. Cjem. 2015;17:107-14. https://doi.org/10.2310/8000.2013.131270.

3. Lebus GF, Collinge CA. Research in a non-academic setting: it can be done. J Orthop Trauma. 2011;25(Suppl 3):S128-30. https ://doi.org/10.1097/BOT.0b013e318237b39b.

4. Calder LA, Abu-Laban RB, Artz JD, McLeod S, Blackie B, Das B, et al. CAEP 2014 Academic Symposium: "How to make research succeed in your department: promoting excellence in Canadian emergency medicine resident research.” CJEM. 2015;17:591-9. https://doi.org/10.1017/cem.2015.90.
5. Perry JJ, Snider CE, Artz JD, Stiell IG, Shaeri S, McLeod S, et al. CAEP 2014 Academic Symposium: "How to make research succeed in your emergency department: How to develop and train career researchers in emergency medicine." CJEM. 2015;17:334 43. https://doi.org/10.1017/cem.2015.63.

6. Vaillancourt C, Rowe BH, Artz JD, Green R, Émond M, Thiruganasambandamoorthy V, et al. CAEP 2014 Academic symposium: "How to make research succeed in your department: How to fund your research program." CJEM. 2015;17:453-61. https:// doi.org/10.1017/cem.2015.58.

7. CAEP Academic Consultation. Available at https://caep.ca/emcommunity/academic-section/academic-consultation/. Accessed 4 Nov 2020

8. Tseng EK, Jo D, Shih AW, De Wit K, Chan TM. Window to the unknown: using storytelling to identify learning needs for the intrinsic competencies within an online needs assessment. AEM Educ Train. 2019;3:179-87. https://doi.org/10.1002/aet2.10315.

9. McRae AD, Taljaard M, Weijer C. Cluster-randomized trials: a closer look. Clin Trials. 2016;13:294-300. https://doi. org/10.1177/1740774516629405.

10. Perry JJ, Sivilotti MLA, Sutherland J, Hohl CM, Émond M, Calder LA, et al. Validation of the Ottawa Subarachnoid Hemorrhage Rule in patients with acute headache. CMAJ. 2017;189:E137985. https://doi.org/10.1503/cmaj.170072.

11. Whalen S, Goldstein J, Urquhart R, Carter AJE. The novel role of paramedics in collaborative emergency centres aligns with their professional identity: a qualitative analysis. CJEM. 2018;20:518 22. https://doi.org/10.1017/cem.2018.401.

12. McLeod SL, McCarron J, Ahmed T, Grewal K, Mittmann N, Scott $\mathrm{S}$, et al. Interrater reliability, accuracy, and triage time pre- and post-implementation of a real-time electronic triage decisionsupport tool. Ann Emerg Med. 2020;75:524-31. https://doi. org/10.1016/j.annemergmed.2019.07.048.

13. NCER. Available at https://ncer.ca. Accessed 4 Nov 2020.

14. Pediatrics Research Consortium. Available at https://perc.resea rch.chop.edu/. Accessed 4 Nov 2020.

15. Canadian Critical Care Trials Group. Available at https://ccetg.ca/ Home.aspx. Accessed 4 Nov 2020.

16. Canadian Resuscitation Outcomes Consortium. Available at https ://canroc.org/. Accessed 4 Nov 2020.

17. Knowledge Translation (KT) Canada. Available at: https://www. ctrc-ccrt.ca/. Accessed 4 Nov 2020.

18. Carpenter CR, Cone DC, Sarli CC. Using publication metrics to highlight academic productivity and research impact. Acad Emerg Med. 2014;21:1160-72. https://doi.org/10.1111/acem.12482.

19. Bragard I, Dupuis G, Fleet R. Quality of work life, burnout, and stress in emergency department physicians: a qualitative review. Eur J Emerg Med. 2015;22:227-34. https://doi.org/10.1097/ MEJ.0000000000000194.

20. De Wit K, Mercuri M, Wallner C, Clayton N, Archambault P, Ritchie K, et al. Canadian emergency physician psychological distress and burnout during the first 10 weeks of COVID-19: a mixed-methods study. J Am Coll Emerg Physicians Open. 2020;14:17. https://doi.org/10.1002/emp2.12225. 